\title{
Harran Ovası Yaygın Toprak Serilerinin Fiziksel, Kimyasal ve Morfolojik Özellikleri
}

\author{
Ali Rıza ÖZTÜRKMEN*, Emrah RAMAZANOĞLU, Murat ÇAKMAKLI, \\ Eda ÇAKMAKLI \\ Harran Üniversitesi Ziraat Fakültesi, Toprak Bilimi ve Bitki Besleme Bölümü, Şanlıurfa \\ (ORCID: 0000-0001-5575-3278)(ORCID: 0000-0002-7921-5703) \\ (ORCID: 0000-0002-9998-5094) (ORCID: 0000-0002-6842-2344)
}

\begin{abstract}
Öz
Toplam 225000 hektarlık Harran Ovası büyük bir tarımsal potansiyele sahiptir. Bu topraklar üzerinde bazı çalışmalar yapılmış olmasına rağmen, önemi dolayısıyla ayrıntılı çalışmalara büyük bir ihtiyaç duyulmaktadır. Bu çalışma, Harran ovasında yaygın toprak serilerinin (Harran, İkizce, Bellitaş, Çekçek) fiziksel, kimyasal ve morfolojik özelliklerinin belirlenmesi amacı ile yapılmıştır. Harran ovasında koordinatları alınan 4 farklı noktada toprak profilleri açılarak horizon esasına göre toprak örnekleri alınmıştır. Çalışma elde edilen sonuçlara göre incelenen toprak profillerinin kireç içerikleri bakımından yüksek, organik madde bakımında toprakların çoğunda az olduğu belirlenmiştir. Toprakların katyon değişim kapasiteleri ise toprakların kil içeriklerine göre değişim göstermekte olup genellikle $22-50 \mathrm{cmol} \mathrm{kg}^{-1}$ arasında değiştiği belirlenmiştir. Toprak reaksiyonu $(\mathrm{pH})$ açısından $7,1-8,5$ arasında değerler alan topraklar nötr ve hafif alkali olarak bulunmuştur.
\end{abstract}

Anahtar Kelime: Harran Ovası, Toprak Serileri, İkizce, Bellitaş, Çekçek.

\section{Physical, Chemical, and Morphological Properties of Harran Plain Common Soil Series}

\begin{abstract}
The Harran Plain, with a total area of 225000 hectares, has great agricultural potential. Although some studies have been done on these lands, detailed studies are needed due to their importance. This study was conducted to determine the physical, chemical, and morphological characteristics of common soil series (Harran, İkizce, Bellitas, Cekcek) in the Harran plain. Soil samples were taken based on the horizon by opening soil profiles at 4 different points in the Harran plain. According to the results of the study, it was determined that the analyzed soil profiles were high in lime content and low in organic matter in most soils. The cation exchange capacities of the soils vary according to the clay content of the soils, and it has been determined that it generally varies between 22$50 \mathrm{cmol} \mathrm{kg}{ }^{-1}$. Soils with values between 7,1 and 8,5 in terms of soil reaction $(\mathrm{pH})$ were found to be neutral and slightly alkaline.
\end{abstract}

Keywords: Harran Plain, Soil Series, İkizce, Bellitas, Cekcek.

\section{Giriş}

Toprak genel olarak canlılar için gıda teminini sağlayan bitkisel üretimin yoğun olarak yapıldığı, yeryüzünde yaşayan bütün canlılar için barınma ve yaşamını ikame ettiği doğal bir ortamdır [1]. Nüfus artışındaki hız ile birlikte arazi kullanımındaki değişim de kaçınılmaz sonuç olarak karşımıza çıkmakta olup, profesyonel planlama yapılmadığında bu durum büyük ekonomik sorunlara neden olmaktadır [2]. Mevcut tarım arazilerinin verimlilik durumlarının tespiti ve toprak kalitesinin yükseltilmesi yeryüzünde yaşayan canlılar için önemli olup, sürdürülebilir tarımsal üretim için toprakların yönetilmesi ise zorunlu bir durum olmaktadır [3]. Toprak verimliliği toprakların birim alandan yüksek verimin alınmasını sağlayan önemli bir parametredir [4]. Bitkisel üretimde hedeflenen kalite ve miktarda ürünün alınması

"Sorumlu yazar: arozturkmen@ harran.edu.tr

Geliş Tarihi: 28.09.2020, Kabul Tarihi: 11.01.2021 
için toprakta bitkiler için gerekli olan yarayışlı bitki besin elementlerinin yeterli olması gerekmektedir. $\mathrm{Bu}$ amaçla da toprakların verimlilik durumlarını belirlemeye yönelik ülkemizde birçok çalışma yapılmıştır. Güzel vd. [5] Harran ovasında farklı serilerdeki topraklarda bitkiler için yarayışlı mikro besin elementlerin kapsamlarının belirlendiği çalışmada; çinko miktarının 0,16-1,20 mg/kg, demirin $2,68-6,40 \mathrm{mg} / \mathrm{kg}$, bakırın $0,65-8,18 \mathrm{mg} / \mathrm{kg}$ ve manganın $2,62-13,05 \mathrm{mg} / \mathrm{kg}$ arasında değiştiğini belirlemiş ve bu mikro elementlerin ortalama olarak sırasılyla $0,43,4,72,1,60$ ve $6,67 \mathrm{mg} / \mathrm{kg}$ olarak belirlenmiştir. Çalışma sonucunda toprak serilerinde çinkonun \%80, demirin ise $\% 40$ yeter seviyesinin altında olduğunu bildirmişlerdir [5]. Güneydoğu Anadolu Projesi (GAP) tarımda sulanabilir alanlar ile yüksek verim elde etme ve toplumun kalkınmasını hedef alan bir proje olarak hayata geçirilmiştir. Projenin tüm etapları tamamlanmamış olup, arazilerin bir kısmı sulanabilir duruma gelmiştir. Sulama ile bilirlikte bitkisel ürün deseni değişmiş, verim artmış ve çiftçilerin gelir düzeylerinde yükselmeler görülmüştür. Bölgede ise tarıma dayalı sanayi sektöründe olumlu gelişmeler yaşanmıştır. Bu olumlu gelişmelerin sağlanmasına karşın ürün deseninin farklılaşması ile birlikte tarımda su, gübre ve çeşitli kimyasalların kullanımında artmalar meydana gelmiş bu da beraberinde birçok sorunu tetiklemiştir [6]. Tektonik olaylar sonucunda Güneydoğu Anadolu'da irili ufaklı birçok horst ve grabenler oluşmuştur. Harran Ovası da bölgede birçok horst ve grabenlerin oluştuğu önemli alanlardan biridir [7]. Ergene [8], Fırat Nehri ile Amonos Dağları Arasındaki Bölgede Ova topraklarının baskın kil minerallerinin belirlenmesi çalışmasında açılan dört toprak profilinde yapılan analizler sonucunda illit miktarının \%40 üzerinde, kaolinitin \%10-40 arasında; kuvars, klorit, vermikülit ve amorf maddeyi \%10'un altında olduğunu belirlemişlerdir. Dinç ve Ark. [9], Harran Ovasında toprakların fiziksel, kimyasal, minerolojik ve mikromorfolojik özelliklerinin belirlenmesi için açılan 25 toprak profilinde toprakların killi tekstürde ve kireç içeriklerinin yüksek olduğu belirlenmiş, toprakta makro bitki besin elementlerinden potasyum miktarının yeterli, fosforun ise yetersiz olduğu belirlemişlerdir. Harran Ovası'nda toplam fosfor kapsamlarını 0-20 cm toprak derinliğinde $343-894 \mathrm{mg} / \mathrm{kg}, 20-40 \mathrm{~cm}$ 'de $313-881 \mathrm{mg} / \mathrm{kg}$ ve $40-60 \mathrm{~cm}$ 'de ise $298-551 \mathrm{mg} / \mathrm{kg}$ aralığında olduğunu, topraklarının kil ve kireç içeriğinin yüksek olmasından dolayı fosforun toprakta suda çözünmez halde bulunduğunu belirtmiştir [10].

Harran ovasının kuzeyinde yapılan bir çalışmada farklı meyve bahçelerinden alınan toprak örneklerinde yapılan analizler sonucunda toprakların yüksek kireç içeriğe sahip oldukları ve makro besin elementlerinden yarayışlı potasyumun tüm meyve bahçelerinde yükssek olduğunu bildirmiştir [11]. Bu çalışmada Harran Ovasında yaygın toprak serilerinin (Harran, Bellitaş, İkizce, Çekçek) fiziksel ve kimyasal özelliklerinin belirlenmesi amaçlanmıştır.

\section{Materyal ve Metot}

\subsection{Calıșma Alanları}

Çalışmada incelenen toprak serileri Harran Ovası Güneydoğu Anadolu Bölgesinde $36^{\circ} 47^{\prime}$ ve $39^{\circ} 15^{\prime}$ doğu boylamları, $36^{\circ} 40^{\prime}$ ve $37^{\circ} 41^{\prime}$ kuzey enlemleri arasında güneyde Suriye sinırı, kuzeyde Germuş ve Şanlıurfa dağları, batısında Fatik dağları doğusunda ise Tektek dağları bulunmaktadır. Toplam 225 000 hektar olan Harran Ovasında yapılan detaylı çalışmalar sonucu 25 toprak serisi (Şekil 1) belirlemişlerdir [9].

\subsection{Metot}

2006 yılında seri esasına göre tanımlanmış profillerden 2017 yılında, batı-doğu yaygın olan serileri üzerinde bulunduran ve ovayı ikiye bölerek, tüm ovayı temsil eden 4 farklı profilden alınmış olan toprak örnekleri, horizon esası itibarıyla [12] göre sınıflandırılarak tanımlanmıştır [19]. Analizler için hazır hale getirilen toprak örneklerinde bazı fiziksel ve kimyasal analizler yapılmışıtı. Saturasyon (\%) miktarı [13] metoduna göre, toprak reaksiyonu $(\mathrm{pH})$ saturasyon çamurunda [14], toprak bünye tayini (Hidrometre metoduyla), kalsiyum Karbonat (\%) Scheibler kalsimetresiyle ile [15], toplam tuz (\%) miktarı toprak örneklerinin elektriki iletkenlik aletinin çamur hücresine yerleştirilmesiyle belirlenmiştir [16]. Organik Madde (\%) yaş yakma metodu kullanılarak belirlenmiştir [17]. Katyon değişim kapasitesi $1.0 \mathrm{~N} \mathrm{NaOAc} \mathrm{çözeltisi} \mathrm{kullanılarak} \mathrm{yapılmıştır[18].}$ 


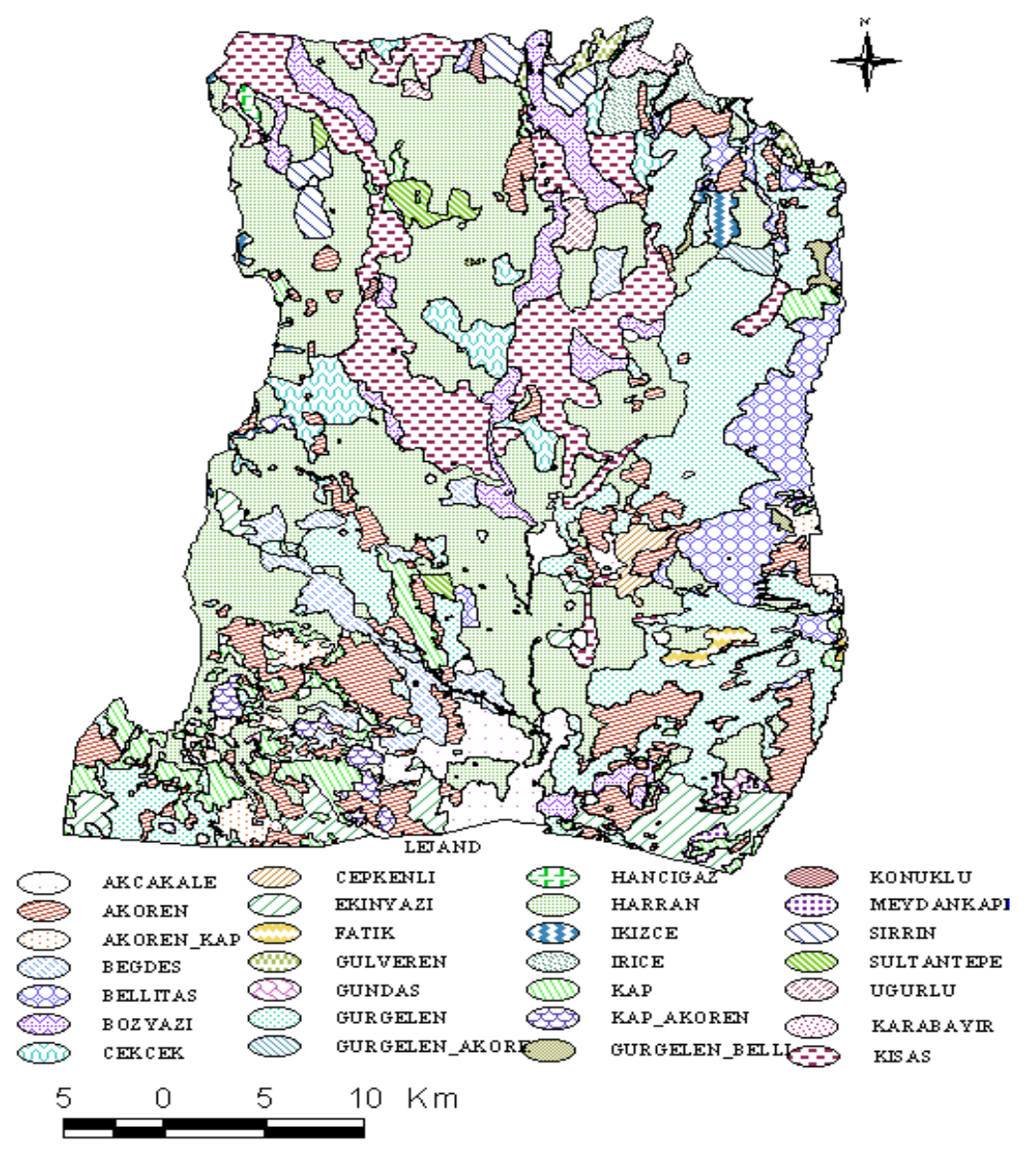

Şekil 1. Harran Ovasının toprak serileri haritası [9]

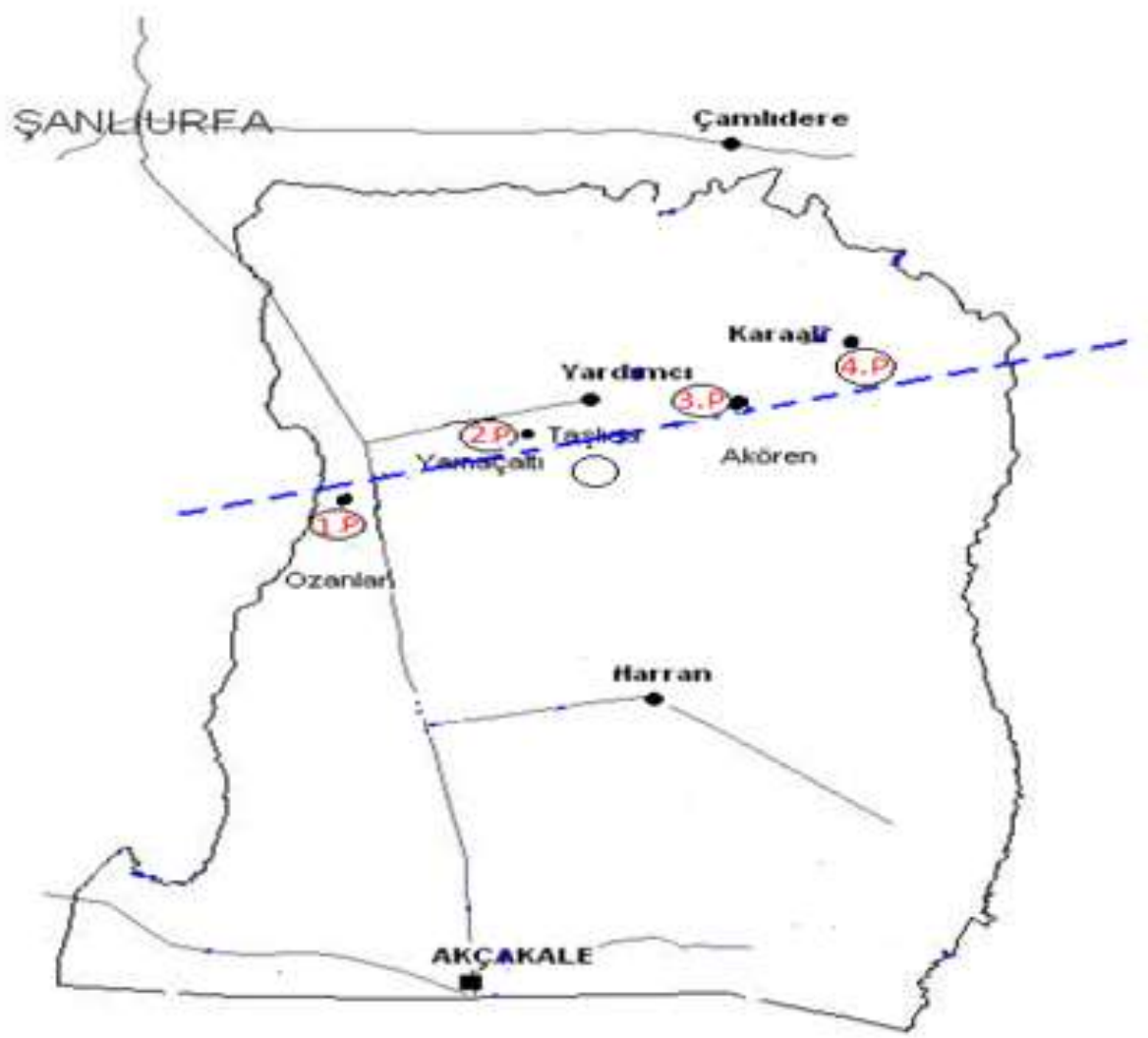

Transekt

Şekil 2. Toprak profili açılan noktalar 


\section{Bulgular ve Tartışma}

\section{1. Çekçek toprak serisi}

Toprak reaksiyonu (pH) 8,08-8,38 arasında, $\mathrm{EC}(\mathrm{dS} / \mathrm{m})$ 0,46- 1,06 arasında, $\mathrm{CaCO}_{3}$ içerikleri \% 19,4831,96 arasında, organik Madde içerikleri \%0,21-1,19 arasında, KDK değerleri (Cmol/kg) 29,65-48,54 arasında, Kum \%20,36-31,91, Silt \%30,24-41,56 ve Kil içeriği \%26,53-44,62 arasında değerlerde belirlenmiştir (Tablo 5). Toprak profili Ozanlar köyünün yaklaşık $500 \mathrm{~m}$ kuzey doğusunda 2,50 m derinliğinde açılmış (Şekil 3), profilin temsil ettiği Çekçek serisi topraklarının strüktür yapısının çok iyi geliştiği, altta ve üstte 2 horizon mevcut olup, horizonların tekstür bakımından birbirinden çok farklı olduğu gözlenmiştir. Üst horizonların alt horizonlara göre genellikle granüler bir yapıda ve kolayca dağılmakta ve tüm profilin çok kuru olduğu gözlenmiştir. Profil yaklaşık $100 \mathrm{~cm}$ 'ye kadar olan horizon strüktürü gevşek bir kıvamdadır. En alt toprak yani profilin $120 \mathrm{~cm}$ 'den sonraki kısmında kayma yüzeyleri ve kireç benekleri gözlenmiştir. Yukarıdan aşağıya inildikçe $120 \mathrm{~cm}$ 'den sonra kireç miktarı artmaktadır. Bu profilde çok miktarda ve iç içe girmiş durumda bitki kökü varlığı gözlenmiştir. Profil genel olarak siltli kil tekstürlüdür (Tablo 1). Sonuçlar alanda başka araştırmacıların yaptığı çalışmalarla benzerlik göstermektedir $[9,19,20]$.

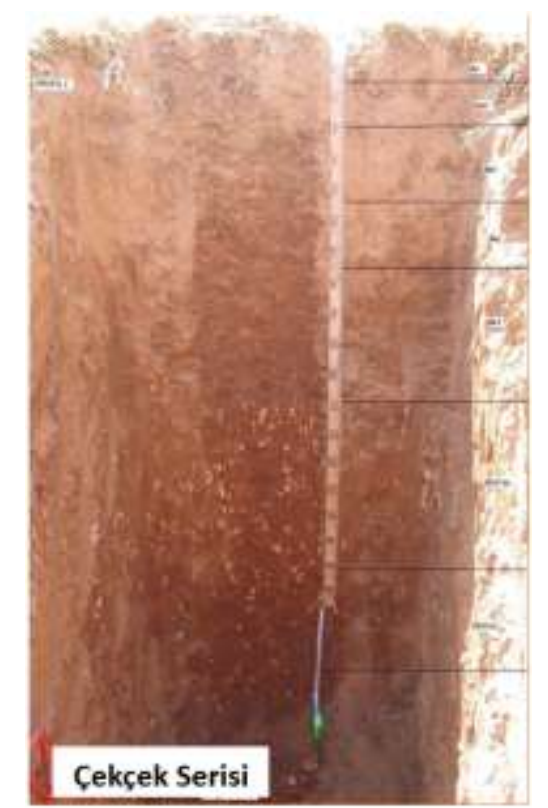

Şekil 3. Çekçek serisi toprak profili

Tablo 1. Çekçek serisi profili horizonlarına ait morfolojik özellikler

\begin{tabular}{|c|c|c|c|c|c|c|c|}
\hline Derinlik $(\mathrm{cm})$ & Horizon & Tekstür** & Renk (I & nli) & Strüktür * & Yoğunluk & Geçiş sınırı \\
\hline \multicolumn{8}{|c|}{ ÇEKÇEK SERİSI } \\
\hline $0-15$ & Ap & $\mathrm{SiC}$ & $10 \mathrm{YR}$ & $4 / 4$ & Grn & Zayıf sertlikte & Düz, az belirgin \\
\hline $15-33$ & $\mathrm{~A}_{1}$ & $\mathrm{SiC}$ & $10 \mathrm{YR}$ & $4 / 4$ & Z kç yrkş blst & Zayıf sertlikte & Düz, az belirgin \\
\hline $33-55$ & $\mathrm{Bw} 1$ & $\mathrm{SiC}$ & $10 \mathrm{YR}$ & $4 / 4$ & $\begin{array}{c}\text { Kv oby yrkş } \\
\text { blst }\end{array}$ & Zayıf sertlikte & Düz, az belirgin \\
\hline $55-76$ & $\mathrm{Bw}_{2}$ & $\mathrm{SiC}$ & $10 \mathrm{YR}$ & $4 / 4$ & $\begin{array}{c}\text { O ve by okv } \\
\text { kș blst }\end{array}$ & Orta kuvvetli & Dalgalı, az belirgin \\
\hline $76-120$ & $\mathrm{Bw}_{3}$ & $\mathrm{SiC}$ & $10 \mathrm{YR}$ & $4 / 4$ & $\begin{array}{c}\mathrm{O} \text { ve by kv kş } \\
\text { blst }\end{array}$ & Orta kuvvetli & Dalgalı, az belirgin \\
\hline $120-182$ & $\mathrm{Bkb}_{1}$ & $\mathrm{SiC}$ & 7.5YR & $4 / 6$ & $\begin{array}{c}\text { By kv kş } \\
\text { blst/mn }\end{array}$ & Orta kuvvetli & Dalgalı, az belirgin \\
\hline $182-+$ & $\mathrm{Bkb}_{2 \mathrm{ss}}$ & $\mathrm{SiC}$ & $7.5 \mathrm{YR}$ & $4 / 4$ & $\begin{array}{l}\text { By kv kş } \\
\text { blst/ss/mn }\end{array}$ & Orta kuvvetli & Dalgalı, az belirgin \\
\hline
\end{tabular}

*Kısaltmalar: kç-küęük, yrkş-yarı köşeli, blst-blok strüktür, okv-orta kuvvette, oby-orta büyüklükte, z-zayıf, ssslicken side, kş-köşeli, kv-kuvvetli, yr-yarı, by-büyük, o-orta, mn-mangan birikintileri.

**Kısaltmalar: SiC-siltli kil 


\subsection{Harran toprak serisi}

Toprak reaksiyonu $(\mathrm{pH}) 7,92-8,44$ arasında, $\mathrm{EC}(\mathrm{dS} / \mathrm{m})$ 0,24 - 1,05 arasında, $\mathrm{CaCO}_{3}$ içerikleri \%18,71 - 31,96 arasında, Organik Madde içerikleri \%0,39 - 1,69 arasında, KDK değerleri (Cmol $/ \mathrm{kg})$ 31,24 46,01 arasında, Kum \%11,28 - 21,03, Silt \%23,45 - 29,53 ve Kil \%49,91 - 61,36 arasında değişmiş̧ir (Tablo 5). Taşlıca köyünde açılmış olan profilin (Şekil 4) temsil ettiği Harran serisi toprakları düze yakın hafif eğimli ve oldukça derin topraklardır. Kırmızı renkli horizonları ile killi tekstürlüdür. Üst toprak oldukça iri ve sert, köşeli blok strüktür yapısındadır. Alt toprak iri sayılabilecek orta sertlikte köşeli blok strüktür yapısındadır. Alt toprakta derinlik artması ile sekonder kireç miktarının arttığı tespit edilmiştir. Tüm profil oldukça kireçlidir. A, B ve C horizonlu topraklardır ve toprak profilinde çakıllar bulunmaktadır (Tablo 2). Sonuçlar alanda başka araştırmacıların yaptığı çalışmalarla benzerlik göstermektedir $[9,19,20]$.

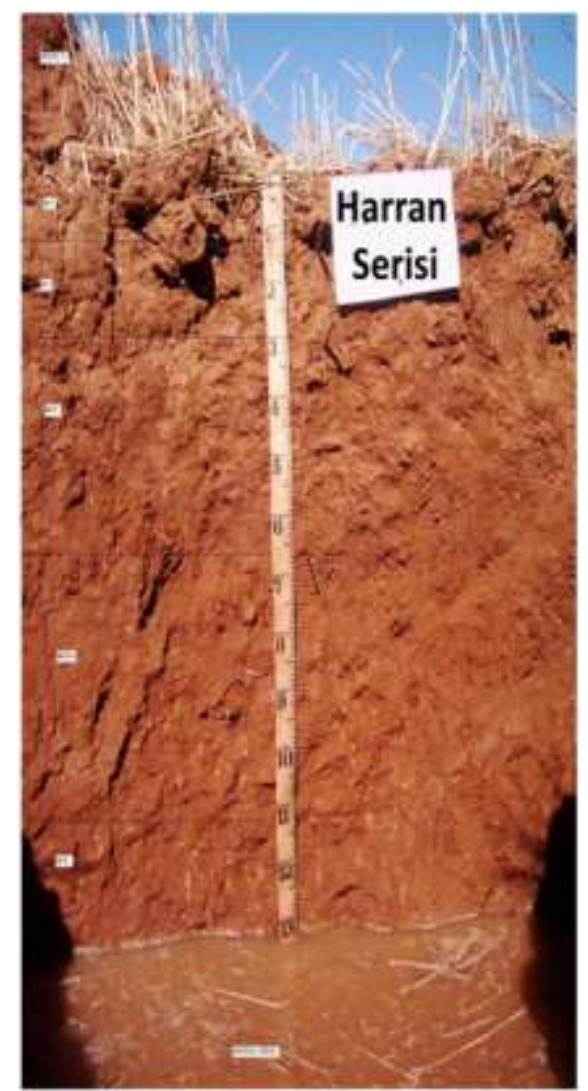

Şekil 4. Harran serisi toprak profili

Tablo 2. Harran serisi profili horizonlarına ait morfolojik özellikler

\begin{tabular}{|c|c|c|c|c|c|c|c|}
\hline Derinlik $(\mathrm{cm})$ & Horizon & Tekstür ** & \multicolumn{2}{|c|}{ Renk (Nemli) } & Strüktür* & Yoğunluk & Geçiş sınırı \\
\hline \multicolumn{8}{|c|}{ HARRAN SERISI } \\
\hline $0-12$ & Ap & $\mathrm{C}$ & 7,5 YR & $4 / 4$ & $\begin{array}{c}\text { Çby okv yrkş } \\
\text { blst }\end{array}$ & Orta kuvvetl & $\begin{array}{c}\text { Dalgali, az } \\
\text { belirgin }\end{array}$ \\
\hline $12-30$ & $\mathrm{~A}_{1}$ & $\mathrm{C}$ & 7,5 YR & $4 / 4$ & $\begin{array}{c}\text { By okv yrkş } \\
\text { blst }\end{array}$ & $\begin{array}{c}\text { Orta } \\
\text { kuvvetli }\end{array}$ & $\begin{array}{c}\text { Dalgalı, az } \\
\text { belirgin }\end{array}$ \\
\hline $30-66$ & $\mathrm{Bwk}_{1}$ & $\mathrm{C}$ & 7,5 YR & $3 / 4$ & $\begin{array}{c}\text { By okv yrkş } \\
\text { blst }\end{array}$ & $\begin{array}{c}\text { Orta } \\
\text { kuvvetli }\end{array}$ & $\begin{array}{c}\text { Dalgali, az } \\
\text { belirgin }\end{array}$ \\
\hline $66-112$ & $\mathrm{Bwk}_{2 \mathrm{SS}}$ & $\mathrm{C}$ & 7,5 YR & $4 / 4$ & By kv kş blst & Kuvvetli & Dalgal, belirgin \\
\hline $112-140$ & $\mathrm{Bwk}_{3}$ & $\mathrm{C}$ & 7,5 YR & $4 / 4$ & $\begin{array}{c}\text { By okv kş } \\
\text { blst }\end{array}$ & $\begin{array}{c}\text { Orta } \\
\text { kuvvetli }\end{array}$ & $\begin{array}{c}\text { Dalgal1, az } \\
\text { belirgin }\end{array}$ \\
\hline
\end{tabular}

* Kısaltmalar: yrkş-yarı köşeli, blst-blok strüktür, okv-orta kuvvette, kş-köşeli, kv-kuvvetli, by-büyük, çby-çok büyük.

*** Kisaltmalar: C-kil 


\section{3. İkizce toprak serisi}

Toprak reaksiyonu $(\mathrm{pH})$ 7,4 - 7,89 arasında, $\mathrm{EC}(\mathrm{dS} / \mathrm{m})$ 0,42 - 0,92 arasında, $\mathrm{CaCO}_{3}$ içerikleri \% 14,03 - 28,84 arasında, Organik Madde içerikleri \% 0,13 - 1,43 arasında, KDK değerleri (Cmol/kg) 30,49 49,57 arasında, Kum \% 16,56 - 31,32, Silt \% 26,14 - 41,14 ve Kil \%29,74 - 52,50 arasında değerler almıştır (Tablo 5). Karaali ve Akören köylerinin arasında açılmış olan İkizce serisi profillerinin (Şekil 5) temsil ettiği topraklar etek arazilerde düze yakın az eğimli orta derin ve derindir. Profilin üst kısmı kil tekstürlü fakat aşağılara doğru siltli kil tekstürlüdür. En alt horizonlarda kum miktarı artmaktadır. Orta kısımlarda azda olsa kayma yüzeyleri tespit edilmiştir; alt kısımlarda yer yer mangan benekleri de görülmüştür. Yaklaşık $190 \mathrm{~cm}$ ' de bir çakıl tabakası bulunmaktadır. Profilin üst kısımlarında strüktür orta kuvvette, kaba, yarı köşeli yapıda olduğu alt kısımların ise orta kuvvette, orta kaba, köşeli blok yapıdadır (Tablo 3). Horizonlar arası sınırlar belirgindir. Sonuçlar alanda başka araştırmacıların yaptığ çalışmalarla benzerlik göstermektedir $[9,19,20]$.

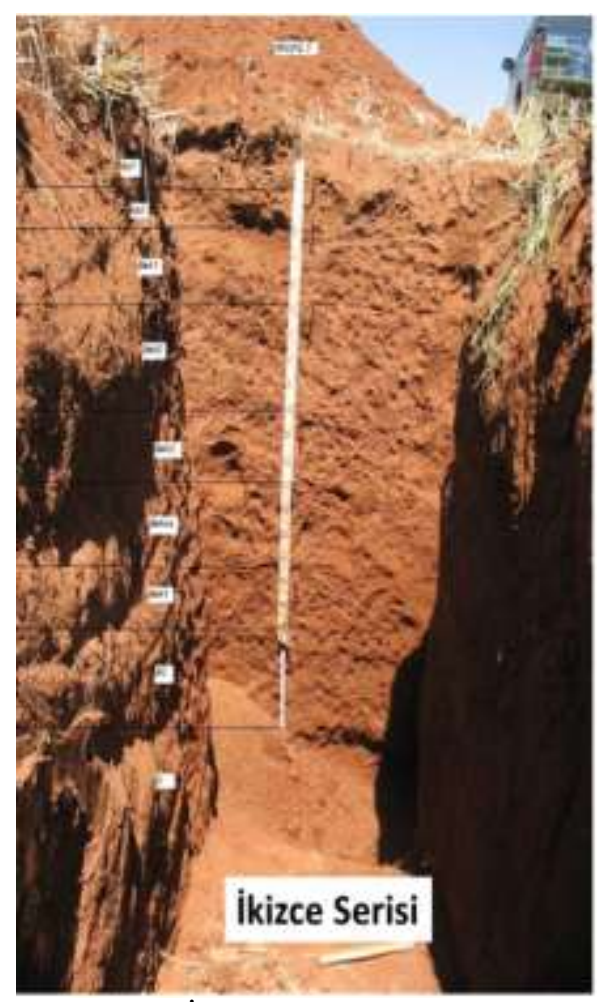

Şekil 5. İkizce serisi toprak profili

Tablo 3. İkizce serisi profili horizonlarına ait morfolojik özellikler

\begin{tabular}{|c|c|c|c|c|c|c|c|}
\hline Derinlik $(\mathrm{cm})$ & Horizon & Tekstür** & Renk (N & & Strüktür * & Yoğunluk & Geçiş sınırı \\
\hline \multicolumn{8}{|c|}{ İKIZCE SERİSİ } \\
\hline $0-14$ & Ap & $\mathrm{C}$ & 7,5 YR & $4 / 4$ & Grn & Orta kuvvetli & Dalgalı, belirgin \\
\hline $14-30$ & $\mathrm{~A}_{1}$ & $\mathrm{C}$ & 7,5 YR & $4 / 6$ & By okv kş blst & Orta kuvvetli & Dalgal1, belirgin \\
\hline $30-60$ & $\mathrm{Bwk}_{1}$ & $\mathrm{C}$ & $7,5 \mathrm{YR}$ & $4 / 4$ & Oby z kş blst & Orta kuvvetli & Dalgalı, belirgin \\
\hline $60-103$ & $\mathrm{Bwk}_{2}$ & $\mathrm{C}$ & 7,5 YR & $4 / 4$ & $\begin{array}{c}\text { Oby okv kş } \\
\text { blst }\end{array}$ & Orta kuvvetli & Dalgal1, belirgin \\
\hline $103-130$ & $\mathrm{Bwk}_{3}$ & GC & $7,5 \mathrm{YR}$ & $4 / 4$ & By okv kş blst & Kuvvetli & Düz, belirgin \\
\hline $130-168$ & $\mathrm{Bwk}_{\mathrm{ss}}$ & $\mathrm{SiC}$ & $5 \mathrm{YR}$ & $3 / 4$ & By okv kş blst & Zayıf sertlikte & Düz, belirgin \\
\hline $168-190$ & $\mathrm{Bk}_{1}$ & $\mathrm{SiC}$ & $7,5 \mathrm{YR}$ & $3 / 4$ & By okv kş blst & Zayıf sertlikte & Düz, belirgin \\
\hline $190-249$ & $\mathrm{BC}$ & GSiC & $5 \mathrm{YR}$ & $4 / 4$ & $\begin{array}{c}\text { Çby okv kş } \\
\text { blst }\end{array}$ & Orta kuvvetli & Düz, belirgin \\
\hline $249-+$ & $\mathrm{C}$ & GC & 7,5 YR & $4 / 4$ & $\begin{array}{c}\text { By okv yr kş } \\
\text { blst }\end{array}$ & Orta kuvvetli & Dalgal1, belirgin \\
\hline
\end{tabular}

*Kısaltmalar- 1: yrkş-yarı köşeli, bıst-blok strüktürokv-orta kuvvette, z-zayıf, kş-köşeli, yr-yarı, by-büyük, çby-çok büyük,

**Kısaltmalar: C-kil, SiC-siltli kil, GC-çakıllı kil, GSiC-çakıllı siltli kil, 


\subsection{Bellitaş toprak serisi}

Toprak reaksiyonu $(\mathrm{pH}) 7,65-8,45$ arasında, $\mathrm{EC}(\mathrm{dS} / \mathrm{m})$ 0,53 - 1,25 arasında, $\mathrm{CaCO}_{3}$ içerikleri \% 26,50 - 41,31 arasında, Organik Madde içerikleri \% 0,47 - 1,26 arasında, KDK değerleri (C mol/kg) 29,19 41,94 arasında, Kum \% 13,46 - 24,11, Silt \% 22,79 - 36,15 ve Kil \% 39,74 - 59,24 arasinda değerler almıştır (Tablo 5). Karaali köyünün yaklaşık 1 km kuzeyinde açılmış olan profilin temsil ettiği Bellitaş serisi (Şekil 6) toprakları koluviyal ana materyalli düşük eğimli derin topraklardır. Yaklaşık $250 \mathrm{~cm}$ 'de (altta) çakıl birikimi ile birlikte $120 \mathrm{~cm}$ 'de bir çakıl tabakası daha var olduğu görülmüştür. Bu çakılların sellerle tepelerden ovaya doğru taşındığı düşünülmektedir. Ovanın kenarında açılan profillerde rastlanan taş katları bölgenin zaman zaman taşkınlarla karşı karşıya geldiğini göstermektedir. Taban suyu 286 cm'de görülmüştür. Yüzey toprağı ince granüler yarı köşeli blok strüktürlü, alt horizonlar ise orta büyüklükte orta kuvvette yarı köşeli blok strüktüre sahiptir. Bu toprak derin profilli ve iyi strüktürel yapısından dolayı kalitelidir ve bu bölgenin en verimli toprağı olduğu düşünülmektedir. Toprak killi ve organik madde miktarı zayıftır (Tablo 4). Sonuçlar alanda başka araştırmacıların yaptı̆̆ benzerlik göstermektedir $[9,19,20]$.

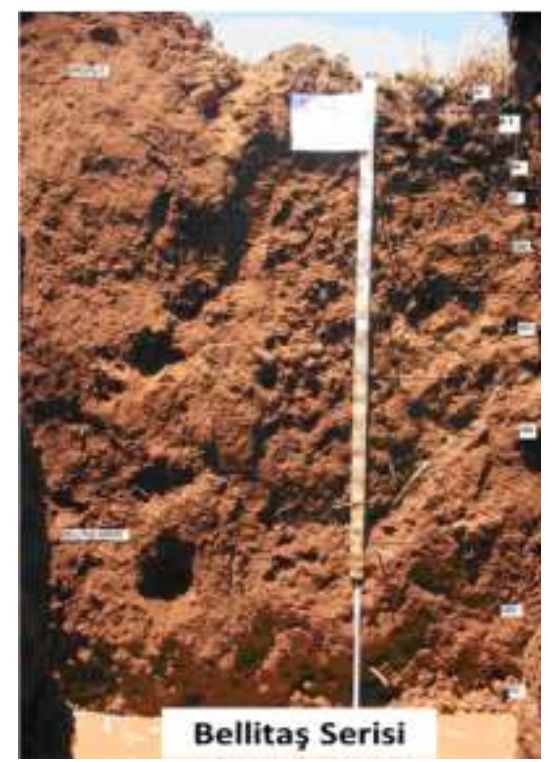

Şekil 5. Bellitaş serisi toprak profili

Tablo 4. Bellitaş serisi profili horizonlarına ait morfolojik özellikler

\begin{tabular}{|c|c|c|c|c|c|c|c|}
\hline Derinlik $(\mathrm{cm})$ & Horizon & Tekstür ** & Renk & mli) & Strüktür * & Yoğunluk & Geçiş sınırı \\
\hline \multicolumn{8}{|c|}{ BELLITASŞ SERISII } \\
\hline $0-10$ & Ap & $\mathrm{C}$ & 7,5 YR & $3 / 4$ & Grn & Orta kuvvetli & $\begin{array}{c}\text { Dalgalı, az } \\
\text { belirgin }\end{array}$ \\
\hline $10-28$ & $\mathrm{~A}_{1}$ & $\mathrm{C}$ & 7,5 YR & $3 / 4$ & Kç okv yrkş blst & Orta kuvvetli & $\begin{array}{c}\text { Dalgal1, az } \\
\text { belirgin }\end{array}$ \\
\hline $28-60$ & $\mathrm{Bw}$ & $\mathrm{C}$ & 7,5 YR & $3 / 4$ & Oby z yrkş blst & Zayıf sertlikte & Dalgalı belirgin \\
\hline $60-94$ & $2 \mathrm{Bw}$ & $\mathrm{C}$ & 7,5 YR & $3 / 4$ & Oby okv yrkş blst & Orta kuvvetli & $\begin{array}{c}\text { Dalgal1, az } \\
\text { belirgin }\end{array}$ \\
\hline $94-125$ & $2 \mathrm{BC}$ & $\mathrm{GC}$ & 7,5 YR & $3 / 4$ & Oby okv yrkş blst & Kuvvetli & Düz, belirgin \\
\hline $125-187$ & $3 \mathrm{~B} w$ & $\mathrm{C}$ & 7,5 YR & $3 / 4$ & Oby okv yrkş blst & Orta kuvvetli & $\begin{array}{c}\text { Dalgal1, az } \\
\text { belirgin }\end{array}$ \\
\hline $187-236$ & $3 \mathrm{BC}$ & $\mathrm{C}$ & 7,5 YR & $4 / 4$ & Oby okv yrkş blst & Orta kuvvetli & $\begin{array}{l}\text { Dalgal1, az } \\
\text { belirgin }\end{array}$ \\
\hline
\end{tabular}

* Kısaltmalar- 1: kç-küçük, yrkş-yarı köşeli, blst-blok strüktür, okv-orta kuvvette, oby-orta büyüklükte, z-zayıf,

**Kısaltmalar: C-kil, GC-çakıllı kil 
Tablo 5. Profil örneklerinin kimyasal analiz sonuçları

\begin{tabular}{|c|c|c|c|c|c|c|c|c|c|}
\hline \multirow{2}{*}{ Profil } & \multirow{2}{*}{$\begin{array}{c}\text { Derinlik } \\
\text { (cm) }\end{array}$} & \multirow{2}{*}{$\mathbf{p H}$} & \multirow{2}{*}{$\begin{array}{c}\text { EC } \\
(\mathbf{d S} / \mathbf{m})\end{array}$} & \multirow{2}{*}{$\begin{array}{c}\mathrm{CaCO}_{3} \\
(\%)\end{array}$} & \multirow{2}{*}{$\begin{array}{c}\text { Org. } \\
\text { Madde } \\
(\%)\end{array}$} & \multirow{2}{*}{$\begin{array}{c}\text { Katyon Değ. } \\
\text { Kap. } \\
(\mathrm{Cmol} / \mathrm{kg})\end{array}$} & \multicolumn{3}{|c|}{ Tekstür } \\
\hline & & & & & & & $\begin{array}{l}\text { Kum } \\
(\%)\end{array}$ & $\begin{array}{l}\text { Silt } \\
(\%)\end{array}$ & $\begin{array}{c}\text { Kil } \\
(\%)\end{array}$ \\
\hline \multirow{5}{*}{ 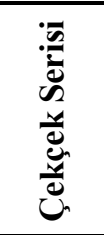 } & $0-15$ & 8,22 & 1,06 & 29,62 & 1,11 & 44,51 & 31,61 & 38,62 & 29,77 \\
\hline & $15-33$ & 8,23 & 0,75 & 28,84 & 1,16 & 33,49 & 31,91 & 41,56 & 26,53 \\
\hline & $33-55$ & 8,14 & 0,68 & 24,94 & 1,19 & 35,05 & 28,47 & 39,34 & 32,19 \\
\hline & $55-76$ & 8,20 & 0,71 & 25,72 & 0,96 & 32,96 & 23,94 & 39,03 & 37,03 \\
\hline & $76-100$ & 8,38 & 0,61 & 31,18 & 0,33 & 33,26 & 28,15 & 30,24 & 41,61 \\
\hline \multirow{5}{*}{ 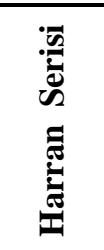 } & $0-12$ & 8,40 & 0,94 & 26,50 & 1,14 & 40,69 & 10,12 & 36,13 & 53,75 \\
\hline & $12-30$ & 8,20 & 1,11 & 24,94 & 1,26 & 33,65 & 8,32 & 36,46 & 55,22 \\
\hline & $30-66$ & 7,77 & 0,56 & 31,18 & 0,83 & 46,94 & 6,03 & 38,32 & 55,65 \\
\hline & 66-112 & 8,05 & 0,94 & 29,62 & 0,81 & 35,62 & 4,16 & 37,16 & 58,68 \\
\hline & $112-140$ & 8,10 & 1,02 & 30,40 & 0,63 & 42,31 & 3,76 & 39,26 & 56,98 \\
\hline \multirow{4}{*}{ 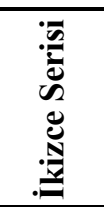 } & $0-14$ & 7,62 & 0,74 & 27,28 & 1,31 & 49,57 & 18,16 & 36,25 & 45,59 \\
\hline & $14-30$ & 7,62 & 0,45 & 27,28 & 1,33 & 47,15 & 16,56 & 34,12 & 49,32 \\
\hline & $30-60$ & 7,40 & 0,42 & 28,84 & 1,27 & 44,28 & 17,52 & 32,45 & 50,03 \\
\hline & $60-103$ & 7,82 & 0,92 & 28,84 & 0,29 & 32,85 & 31,32 & 30,49 & 38,19 \\
\hline \multirow{5}{*}{ 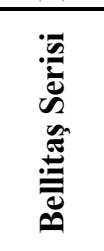 } & $0-10$ & 8,35 & 1,25 & 34,29 & 1,26 & 34,89 & 24,11 & 36,15 & 39,74 \\
\hline & $10-28$ & 8,45 & 0,73 & 32,73 & 1,09 & 41,94 & 20,46 & 32,75 & 46,79 \\
\hline & $28-60$ & 8,22 & 0,79 & 36,63 & 1,11 & 37,62 & 18,64 & 31,15 & 50,21 \\
\hline & $60-94$ & 8,10 & 1,16 & 29,62 & 1,16 & 38,33 & 13,46 & 32,06 & 54,48 \\
\hline & $94-125$ & 7,97 & 0,53 & 26,50 & 0,61 & 30,97 & 15,34 & 27,19 & 57,47 \\
\hline
\end{tabular}

Araştırma alanında çalışılan toprak serilerinde yapılan kimyasal analizler sonucunda: profillerde pH değerleri 7,40 ile 8,45 arasında, EC değerleri 0,42 - 1,25 arasında, $\mathrm{CaCO}_{3}$ değerleri 24,94 -34,29 arasında, organik Madde değerleri 0,29 - 1,33 arasında, Katyon değişim kapasitesi değerleri 30,97 49,57 arasında ve tekstür ise killi, killi tın sınıflarında bulunmuştur.

\section{Sonuç}

Harran Ovasındaki yaygın toprak serileri Harran, Bellitaş, İkizce, Çekçek Serilerinden örnekleme yapılmıştır. Araştırmaya konu olan yaygın toprak serileri Harran, Bellitaş, İkizce, Çekçek Serilerinde $\mathrm{pH}$ nötr ve hafif alkali, $\mathrm{EC}$ değerleri düşük, $\mathrm{CaCO}_{3}$ içerikleri yüksek, Organik Madde içerikleri yetersiz, Katyon değişim kapasitesi yüksek ve tekstür sınıfları ise killi olarak bulunmuştur. Topraklar genellikle yer yer eğimli alanların olduğu belirlenmiştir.

Harran Ovasının sulamaya açılması ile beraber bitkisel üretimde verim artışları görülmüştür. Toprak özelliklerinin tanımlanması ile beraber, ekilecek ürünün seçimi, gübreleme ve sulamada büyük kolaylıklar sağlanacaktır. Sulamada eğimli alanlar için su birikimine dikkat edilmesi ve fazla suyun arazilerden tahliye edilmesi gereken yerlerin olduğu görülmüştür. Harran Ovasında çok geniş tarım arazilerinin olduğu bu nedenle daha fazla toprak profilleri açılarak daha detaylı çalışmaların yapılması gerekmektedir.

\section{Yazarların Katkısı}

Çalışmaya tüm yazarlar eşit oranda katkı sunmuştur.

\section{Çıkar Çatışması Beyanı}

Yazarlar arasında herhangi bir çıkar çatışması bulunmamaktadır.

\section{Araştırma ve Yayın Etiği Beyanı}

Yapılan çalışmada, araştırma ve yayın etiğine uyulmuştur. 


\section{Kaynaklar}

[1] Alabi A.A., Adewale A.O., Adebo B., Ogungbe A.S., Coker J. O., Akinboro F.G., Bolaji G. 2019. Effects of different land uses on soil physical and chemical properties in Odeda LGA, Ogun State, Nigeria. Environ Earth Sci, 78: 207.

[2] Nassar M., Levy R., Noel Keough N., Nassar N.N. 2017. Agricultural Land Use Change and its Drivers in the Palestinian Landscape Under Political Instability, the Case of Tulkarm City. Journal of Borderlands Studies, 34 (3): 377-394.

[3] Kabir B.E., Bashari H., Bassiri M., Mosaddeghi, R.M. 2020. Effects of land-use/cover change on soil hydraulic properties and pore characteristics in a semi-arid region of central Iran. Soil \& Tillage Research, 197: 104478.

[4] Nath J.A., Lal R. 2017. Effects of Tillage Practices and Land Use Management on Soil Aggregates and Soil Organic Carbon in the North Appalachian Region, USA. Pedosphere, 27 (1): 172-176.

[5] Güzel N., Ortaş İ., İbrikçi H. 1991. Harran Ovası Toprak Serilerinde Yararlı Mikroelement Düzeyleri ve Çinko Uygulamasına Karşı Bitkinin Yanıtı. Çukurova Üniv. Zir. Fak. Dergisi, 6 (1): 15-30.

[6] Mermut A.R., Öztürk İ. 2010. Türkiye'nin Tarımsal Gücü ve Geleceği. MÜSİAD Araştırma Raporlar1, İstanbul, ISBN: 978-605-4383-05-4.

[7] D.S.İ. 1972. Harran Ovası Hidrojeolojik Etüdü. DSİ Printing Office, Ankara, 1-49.

[8] Ergene A. 1963. Fırat Nehri ile Amonos Dağları Arasındaki Bölgede Teşekkül Eden Kızıl Topraklar Üzerinde Bir Araştırma (Doktora Tezi). Ankara Üniversitesi Ziraat Fakültesi Yayınları No: 2, Ankara.

[9] Dinç U., Şenol S., Sayın M., Kapur S., Güzel N., Derici R., Yeşilsoy M.Ş., Yegingil İ., Sarı M., Kaya Z., Aydın M., Kettaş F., Berkman A., Çolak A.K., Yılmaz K., Tunçgöğüs B., Çavuşgil V., Özbek H., Gülüt K.Y., Karaman C., Dinç O., Öztürk N., Kara E.E. 1988. Güneydoğu Anadolu Bölgesi Toprakları (Gat) 1. Harran Ovası Türkiye Bilimsel ve Teknik Araştırma Kurumu Tarım ve Ormanc1lik Grubu Proje no: TOAG-504, Adana, 475s.

[10] Saygan P.E. 2007. Harran Ovasındaki Bazı Toprak Serilerinin Fosfor Franksiyonları. Yüksek Lisans Tezi, Harran Üniversitesi, Fen Bilimleri Enstitüsü, Şanlıurfa.

[11] Ramazanoglu E. 2019. Determination and Mapping of the Relationship between Potassium and Ammonium of Calcareous Soils with Different Moisture Content. International Journal of Scientific and Technological Research, 5 (7):17-26.

[12] U.S.Salinity Laboratory Staff. 1954. Diagnosis and Improvement of Saline and Alkali Soils (moisture retantion curve). Dept. of Agri. Handbook 60, USA.

[13] Richards L.A. 1954. Diagnosis and Improvement Saline and Alkaline Soils. U.S. Dep. Agr. Handbook 60, USA.

[14] Black C.A. 1965. Methods of Analysis Agreon. No: 9, Ame. Soc. Agr, Madison Wisconsin, USA.

[15] Gülçur F. 1974. Toprağın Fiziksel ve Kimyasal Analiz Metodları. İstanbul Üniversitesi Orman Fakültesi Yayınları, Yayın no: 1970: 201, Kutulmuş Matbaası, İstanbul.

[16] Jackson M.C. 1962. Soil chemical analysis. Prentice Hall. Inc. Eng. Cliff. USA.

[17] Walkley A., Black I.A. 1934. An examination of the Degtjareff method for determining organic carbon in soils: Effect of variations in digestion conditions and of inorganic soil constituents. Soil Sci., 63: 251-263.

[18] Norman A.G., Chapman H.D. 1965. Cation-Exchange Capacity. Agronomy Monograph. doi:10.2134/agronmonogr9.2.c6.

[19] Çakmaklı M. 2008. Harran Ovası topraklarının kökeni ve oluşum mekanizmaları (jeoloji ve toprak ilişkileri). Doktora Tezi, Harran Üniversitesi, Fen Bilimleri Enstitüsü, Şanlıurfa.

[20] Çakmaklı E. 2018. Harran Ovası yaygın toprak serilerinde su tutma eğrilerinin belirlenmesi. Yüksek Lisans Tezi, Harran Üniversitesi, Fen Bilimleri Enstitüsü, Şanlıurfa. 